\title{
Lapurdum
}

Euskal ikerketen aldizkaria | Revue d'études basques |

Revista de estudios vascos | Basque studies review

$13 \mid 2009$

Numéro XIII

\section{Aldaera eta aldaketa euskararen ezagutzan eta erabileran}

Ipar Euskal Herrian - Inkesta soziolinguistikoen aztertze kritikoa

Jean-Baptiste Coyos

\section{(2) OpenEdition}

Journals

Édition électronique

URL : http://journals.openedition.org/lapurdum/2003

DOI : 10.4000/lapurdum.2003

ISSN : 1965-0655

Éditeur

IKER

Édition imprimée

Date de publication : 1 février 2009

Pagination : 89-97

ISBN : 978-2-86781-409-X

ISSN : $1273-3830$

Référence électronique

Jean-Baptiste Coyos, « Aldaera eta aldaketa euskararen ezagutzan eta erabileran », Lapurdum [Linean],

13 | 2009, Sarean emana----an 15 avril 2013, kontsultatu 20 avril 2019. URL : http://

journals.openedition.org/lapurdum/2003; DOI : 10.4000/lapurdum.2003 


\title{
Aldaera eta aldaketa euskararen ezagutzan eta erabileran Ipar Euskal Herrian- Inkesta soziolinguistikoen aztertze kritikoa
}

\author{
Jean-Baptiste COYOS \\ Iker UMR 5478
}

\section{Laburpena:}

Hizkuntza baten egoera aldatzen da beti, estatistika arloan izan dadin (hiztun kopurua, transmisio-tasa, etab.), edo arlo sinbolikoan izan dadin (hiztunen jarrera, irudikapenak, etab.).

Inkesta soziolinguistikoak baliagarri eta beharrezkoak dira hizkuntzaren egoera haren gizartetestuinguruan ezagutzeko. Euskararen kasuan, bi inkesta mota nagusi ditugu. Galdera askorekiko inkesta handiak non datuak, heinbatean, inkestatuen erantzunetan oinarritzen diren: irudikapenak, autoebaluazioak, iritziak dira datuen iturriak, besteak beste. Bestetik bigarren inkesta motak behaketa zuzenaren bidez emaitzak biltzen ditu eta, horrela, egiazko ahozko erabilera neurtzen du. Baina erabilerari mugatzen da, gaur egun kale erabilerari.

Artikulu honetan inkesten metodologiak, beren mugak eta akatsak aztertu nahi ditugu adibide batzuen bidez, Ipar Euskal Herriko kasua hartuz.

\section{Abstract:}

The situation of a language is always changing, either at the statistical level (number of speakers, transmission rate, etc.) or at the symbolic level (opinion in favour of the language, perceptions, etc.).

Sociolinguistic surveys are usefull and necessary in order to know what the situation of a language is in a given society. In the case of Basque we have two main types of survey. One with structured questionnaires and a lot of questions, based on answers of the interviewees: data have their origins in perceptions, self-appraisal, opinions, among others. The second one is based on direct observation and in that way it gathers the real use of the people observed. Nevertheless, it is limited to language use, street use of Basque at the present time.

In this paper we examine the methodology of these surveys, their limits and defects, taking some examples concerning Northern Basque Country.

Gako hitzak: Euskara, inkesta soziolinguistikoak, epistemologia, metodologia, mugak, akatsak. Keywords: Basque language, sociolinguistic surveys, epistemology, methodology, limits, defects. 
«Aurrerantz oparotasunez jarraitu nahi badugu,

ondo egindakoak sendotzea eta

gizarteari bere ahalegina aitortzea beharrezkoa den bezala

da beharrezkoa eta nahitaezkoa, halaber, kritika»,

Euskararen Aholku batzordea: 18

Frantzian eguneroko hizkuntzan « kritika » hitzak ezezko konnotazioa badu, aipatzen denaren aurka agertzearen adierarekin. Halere, hemen, gauza baten balioaren azterketa esanahian, alde onak eta hutsak azaltze zentzuan hartzen dut. Beraz bere adiera neutroenean.

\section{Ikusmolde epistemologikorako bidean: ikergaia eta metodologia}

Artikulu honetan, Euskal Herrian egiten diren inkesta soziolinguistikoen emaitzei ez natzaie interesatuko ${ }^{1}$. Nire helburua da ikustea zein diren erabiliak diren metodologiak, eta metodologia horien eskasiak, akatsak, mugak ahal bezainbat agertaraztea. Hots hurbilketa honek epistemologikoa izan nahi luke. Adibideetan, Ipar Euskal Herriko kasuari mugatuko natzaio.

Noski, eginen ditudan oharrak egiazko azterketa kritiko baten lehen urratsa dira, ez besterik. Ohar horietarik batzuk nabariak dira, begi-bistakoak. Halere, uste dut oroitaraztekoak direla.

Tokiko inkestak, inkesta monografikoak eta holakoak ez dira kontuan hartuko. Txosten honen helburua ez da inkesta soziolinguistiko horien fidagarritasuna edo balioa dudan jartea, baina erakusten saiatzea zergatik beren emaitzak zentzuz eta neurriz hartu behar ditugun.

\subsection{Hizkuntzen etengabeko aldaera eta aldaketa}

Hizkuntza baten egoera aldatzen da beti, nahiz estatistika arloan (hiztun kopurua, transmisiotasa, etab.), nahiz arlo sinbolikoan (hiztunen jarrera, irudikapenak, etab.)2.

Inkesta soziolinguistikoak baliagarri eta beharrezkoak dira hizkuntzaren egoera gizartean ezagutzeko. Inkestek egoera horren ezagutza intuitiboaren haraindian eramaten gaituzte. Beren helburuen artean hizkuntzaren hiztun-kopuruaren ebaluatzea eta erabileraren neurtzea izan daitezke, baina ere herritarren hizkuntzarekiko jarreren edo hizkuntzari buruzko irudikapenen ezagutzea.

\subsection{Ikergaia ez da emana: soziolinguistek inkesta soziolinguistikoen bidez eraikitzen dute-Errealitatea iragazki batetik}

Baina ikergaia ez da emana, inkesta soziolinguistika prestatu nahian, soziolinguistek, hizkuntzapolitika teknikariek, beren ikergaia sortzen dute (Calvet-Dumont: 11). Alde batetik inkesta teknikak, behaketak berak aztergaia aldatzen du (ibid.). Bestetik, ikerleek inkesta aztergaiaren arabera definitzen, zehazten dute, jakin nahi duten arabera.

Oro har aztertzen duten hizkuntzaren egoera ezagutu nahian, errealitate hori iragazki baten

1. Nola eta zertarako inkesta horiek biltzen dituzten datuak erabiliak diren gizartean, hizkuntza politiketan eta plangintzetan, komunikabideetan... beste ikergai bat da. Ildo horretan, soziolinguistikatik at joanen ginateke.

2. Soziolinguistikaren ekarpenetarik bat izan zen erratea hizkuntzen erabilera asko aldatzen dela, jatorri geografiko eta sozialen arabera, baita ere adin, sexu edo komunikazio egoeren arabera. Aldagai horiek kontuan hartuz, soziolinguistika hizkuntzalaritza estrukturalitatik eta generatibistatik bereizi zen. 
zehar aztertzen dute, beren irudikapenetan oinarritzen den iragazkia. Philippe Blanchet frantses soziolinguista aipatzen dut, adibidez: «Gertaeren errealitatea egiaztatzeko gelditzen da (...). Baina gertaeren errealitatea hautemangarri ote da, eraikitzen diren irudipenen bidez ezpada ?» (1994: $95)^{3}$. Dakigun bezala, galdera horrek bere erantzuna badu. Ez da posible, errealitate soziala emana ez baita. Eraikitzeko da.

Halere, eta horrek gutxitzen ditu inkesta soziolinguistiko horien eskasia metodologikoak:

«Garrantzitsuagoa da irudikapenen eta errealitate erlatiboen funtzionamendu dinamikoak ebaluatzea, analisatzea, kopuru gordin eta sinplistak baino, nahitaez partzialki hautematen baizik ez ditugun kopuruak » (P. Blanchet: 102) .

Argi da egiazko hiztun-kopuruak, adibidez, ez ditugu ezagutzen ahal. Ebalua ditzakegu, ez gehiago.

Ildo berean, Bourhis eta Landry quebectar soziolinguistek diote: « Hiztunek beren hizkuntza komunitatearen bizindarra nola hautematen duten, ebaluazio ,objektiboa' bezain garrantzitsua izan daiteke, zentsu datutan eta instituzio euskarri neurgarritan oinarritua den talde bizindarraren ebaluazioa » (2008: 191)5. Badakigu ere nola duela berrogei urte jadanik Labovek bere lan aitzindarian hizkuntza-komunitatea definitu zuen ez hizkuntza-portaera batzuk partekatzen dituelako, baizik eta hizkuntzari buruzko ebaluazio multzo bat partekatzen duelako.

\section{Bi inkesta mota nagusi Euskal Herrian: metodologiari lotuak diren ezezko alde batzuk \\ 2.1. Euskal Herriko inkesta soziolinguistikoen lehen muga: inkestatuen jarrerak eta iru- dikapenak}

Euskararen kasuan, bi inkesta mota nagusi ditugu Euskal Herri osoa aztergaitzat hartzen dutenak. Ezagunenak galdera askorekiko inkesta handiak dira non datuak inkestatuen jarreren eta irudikapenetan, inkestatuen erantzunetan oinarritzen diren. Horiek dira Eusko Jaurlaritzaren Hizkuntza Politikarako Sailburuordetzak egiten dituen Inkesta Soziolinguistikoa - Euskararen jarraipena inkestak, azkena 2008an IV. Inkesta Soziolinguistikoa 2006 liburuan argitaratua dena. Lau ikerketa-eremu eraiki dira: herritarren hizkuntza-gaitasuna, euskararen transmisioa, euskararen erabilera (etxean, lagunartean, eremu formaletan, etab.) eta euskararekiko jarrerak.

Inkesta mota horri buruz lehen oinarrizko oharra hau da, azpimarratzeko dena eta ongi ezaguna dena. Blanchet aipatzen dut berriz: «Labov eta Bourdieurenganik gaur egun klasikoa den giza-zientzietako inkestei buruzko gogoeta metodologikoak erakutsi digu diskurtsoez, iturriez, berriemaileez mesfidatu behar zela, zeren eta erabilekin korrespondantzian ez diren irudikapenak

3. «Il reste à vérifier la réalité des faits (...). Mais la réalité des faits est-elle perceptible autrement qu'à travers des représentations construites?».

4. «Il est plus important d'évaluer, d'analyser (...) les fonctionnements dynamiques des représentations et des réalités relatives, que des effectifs purs et simplistes qu'on ne percevra de toute façon que très partiellement».

5. «How speakers perceive the vitality of their own language communauty may be as important as 'objective' assessments of group vitality based on census data and measurable institutional support».

6. «La réflexion méthodologique aujourd'hui classique depuis Labov et Bourdieu sur les enquêtes en sciences de l'Homme nous a montré qu'il faut se méfier du discours, des sources et des informateurs car ils mettent en scène des représentations qui ne correspondent pas forcément - consciemment ou non - aux pratiques, et des effets d'accomodation à l'enquêteur et au discours dominant». 
antzezten dituzte, eta bai ere inkestatzaileari eta diskurtso nagusiari egokitze eraginez » (1994: $94-95)^{6}$.

Beraz biltzen ditugun datuak inkestatuen jarreren eta irudikapenen iragazkitik iragan dira. Datuek inkestatuaren hizkuntzaren egiazko erabilera edo egiazko ezagutza ez dituzte ematen, irudi bat bakarrik, inkestatuak eta inkestak berak iragaziak.

\subsection{IV. inkesta soziolinguistikoa 2006: beste muga eta akats batzuk}

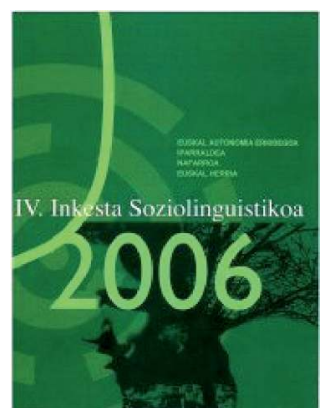

Erantzunak fidagarritzat hartuak dira, printzipioz. Eta erran bezala inkesta horietan datuak inkestatuen erantzunetan oinarritzen dira: irudikapenak, autoebaluazioak, jarrerak eta iritziak dira datuen iturriak. Pernandoren egia badirudi ere, gogoan atxiki behar dugu hori inkesta soziolinguistiken aztertzeko mementoan.

Horrez gain, hona 2006ko inkestaren muga eta akats batzuk. Iparraldeko kasuan, Siadeco enpresak du landa-lana egin, euskara ala frantsesa erabiliz.

\section{- Galdera itxiak}

Galdetegian 30 galdera multzo badira, 72 galdera orotara inkestatuaren ezaugarriei buruzkoak barne (adina, sexua, etab.). Horien artean aukera anitzeko galdera batzuk badira, baina denak itxiak dira, tratamendu sistematikoa eta analisi kuantitatiboa errazteko.

Halere, bistan da, galdera kopurua zabal izanik ere, galdetegiak ikergaia mugatzen du eta erantzunak ere bai. Eta beraz, hiztunak ez du bere ikusmoldea libroki ematen ahal (Calvet-Dumont: $18)$.

\section{- Galdera ez aski zehatza - Fidagarritasunik gabeko kontaketa}

Hirugarren galdera hau da:

«Zoin heinetaraino dakizu eskuara (sic) ? Konprenitzen duzu ongi, aski ongi, doi bat, hitza batzu, fitsik - Mintzatzen duzu ongi, aski ongi, doi bat, hitz batzu, fitsik ? - Irakurtzen... - Izkiriatzen... / Quelles sont vos connaissances en langue basque? - Comprend bien, assez bien, un peu, quelques mots, rien du tout - Parle bien, assez bien, un peu, quelques mots, rien du tout - Lit... - Ecrit...».

Helburua da beraz lau hizkuntza-gaitasunak zein diren jakitea, inkestatuak berak bere gaitasunak ebaluatzen dituelarik.

7. Elebidun hartzaileak « euskaraz ondo mintzatzen ez badira ere, ondo ulertzeko gai diren » pertsonak dira, Eusko Jaurlaritza: 17. 
Inkestatuak hiru multzotan sailkatuak dira: elebidunak, elebidun hartzaileak ${ }^{7}$, erdaldun elebakarrak. Arazo bat agertu da Ipar Euskal Herriko elebidun hartzaileen emaitzetan: 1991an \% 7,04 ziren (14.700), 1996an \% 9,3 (19.700), 2001 an \% 11,7 (25.900) eta 2006an \% 8,6 (19.800). 2006 arte etengabeko gorakada izan da eta bapatean jaitsiera handia.

Beherapen hori nola adierazi? E. Baxokek ondoko hipotesia aitzinatu du, onargarriena nire ustez ${ }^{8}$. Arazoa estatistikoa litzateke: « doi bat » eta « hitz batzu » mintzatzen diren arteko sailkapena ez da fidagarria, bi erranmolde horien adiera hurbilegi baita. Ondorioz, horien arteko muga argi ez litzateke eta inkestatuek nahasiko zituzten, emaitzak batere fidagarriak bilakaraziz.

\section{- Bi hizkuntzetan galdera ez oso berdina}

Inkestatzaileak inkestatuaren arabera euskara ala frantsesa erabil dezake.

Euskarazko eta frantsesezko galderak ez dira beti berdinak, itzultzearengatik, bi hizkuntzen arteko desberdintasunarengatik. Adib. 19. zatian, 4. galdera hola idatzirik da:

«Nahitaezko da haur guziek eskuara (sic) ikastea / Tous les enfants devraient apprendre le basque»?.

Euskaraz modu indikatiboa badugu gehi nahitaezkotasuna. Frantsesez, aldiz, alegiazko (fictif, virtuel) ez bururatua erabilia da. Frantsesezko galderak helburu bat, nahikunde bat adierazten du eta ez nahitaezkotasuna. Beraz erantzunak ez dira osoki konparagarriak.

Ber galdera multzoan ere, 2. galdera ez da berdin-berdina bi hizkuntzetan:

«Nahiago dut inglesa (sic) ikasi eskuara ikasi edo hobetu baino / Je préfère apprendre l'anglais plutôt que le basque ».

Frantsesez euskararen hobetzearen gogoa desagertu da.

Badakigu gainera inkestatu batzuek, euskaldun izanik ere, frantsesez erantzun nahiago dutela eta beraz horietatik batzuek ere beren euskara hobetu nahi lezakete. Xede hori ez da emaitzetan agertuko.

\section{- Bi adierazpenekiko galdera}

Galderen beraien adiera bikoitzarekin beste zailtasun daukagu. Inkestatzaileak inkestatuaren galderen esanahiaren ulermena ez du menperatzen, eta galdera batzuk ulergaitzak izan daitezke. Inkestatzaileak ahalbide gutxi baditu horiek ulertarazteko, galdetegia luzea da eta presatua izan daiteke, telefono bidez informazio bilketan ari delarik.

20. zatian, 4. galdera hola idatzia da:

«Eskuara etxekoekin eta lagunekin erabiltzeko da / Le basque est une langue à utiliser en famille et entre amis».

Bi interpretazio dituzte bederen, nahiz euskaraz, nahiz frantsesez. Bata: familian eta lagunartean euskara erabiltzeko da bakarrik eta ez beste gizarte-eremuetan, beraz interpretazio murritza, edo bestea: euskara da erabilteko den lehen hizkuntza familian eta lagunartean, baina zergatik ez ere beste gizarte-eremuetan.

Gauza bera multzo horren 5. galderarekin:

«Frantsesa ongi menperatzen ez dutelarik haur tikiei eskolan eskuara erakastea ez da ona. / Il

8. Ikus Enbata astekaria, 2008/08/07, 2039. zbk.: 4.

9. Harekin egin ditudan elkarrizketan Erramun Baxokek horietatik ohar batzuk egin dizkit. Eskerrak eman behar dizkiot Erramuni ere Siadecoren inkestako galdetegia eman baitit. 
n'est pas bon d'enseigner le basque à l'école à des petits qui ne maîtrisent pas bien encore le français».

Bi interpretazio dituzte, perpaus erlatiboa esplikatzailea baldin bada ala determinatzailea. Lehen kasuan haur txiki denek ez lukete euskara ikasi behar, frantsesa ongi menperatu baino lehen ; bigarrenean, frantsesa ongi menperatzen ez dutenek bakarrik ikasi behar ez lukete.

\section{- Lagin batzuk murritzak}

Iparraldean, 2.000 inkesta egin dira 2006an: 750 Biarritze-Angelu-Baiona eskualdean, 750 Lapurdi barnealdean eta 500 orotara Nafarroa Beherean eta Zuberoan (IV. Inkesta Soziolinguistikoa 2006: 229).

Batzutan, bilaketa-irizpidearen arabera, lagina murriztegi izan daiteke. Adibidez, « Zein hizkuntzatan hitz egiten du errezago ? » ikergaia delarik, Nafarroa Beherean eta Zuberoan, 16-24 urteko adin taldean 61 dira euskaraz errezago hitz egiten zutelako erantzuna eman dutenak.

Ipar Euskal Herri osoko, erantzunen arabera erdara lehen hizkuntza izan dutenetarik 74 dira euskal elebidun funtzionalak bilakatu direnak. Ipar Euskal Herri osoko berriz, erdara lehen hizkuntza izan dutenetarik 55 dira euskaraz frantsesez baino gehiago ari direnak, erantzunen arabera. Azken adibide horietan, lurraldeka aztertuz, laginak are tipiago lirateke ${ }^{10}$.

\section{- Hizkuntzaren hautaketa hiztunaren arabera eta hizkuntza-gaitasuna}

Azken oharñoa. Hizkuntza ezagutzari buruz, gorago ikusi dugu inkestatuak aitortzen duen gaitasun maila dela inkestatzaileak kontuan hartzen duena, inkesta horien datuen biltzeko prozedura orokorra hola baita.

Halere, 31.ren eta azken zatian inkestazaileak elgarrizketatu euskaldunaren hizkuntza-gaitasuna neurtu behar du eta « euskaraz nola mintzatzen den baloratzeko » sailkaketan kokatu behar $\mathrm{du}$. Lehen galderetan, laugarrenean hain zuzen, « zoin hizkuntzetan eginen dautzut elgarrizketa » galdera pausatzen dio. Beraz, inkestatuak euskara hautatzen baldin badu inkestatuaren hizkuntzagaitasuna gutxi gorabehera neur lezake galderak euskaraz emanez.

Alta pentsa dezakegu, adineko euskaldun zaharren artean bereziki, batzuek frantsesez erantzun nahiago dutela euskaraz ez ezik, haientzat holako egoera formal batean, erran nahi baita inkesta ofizial baten gure kasuan, frantsesa sinesgarriago bailitzateke edo holako irudikapen motarengatik.

\section{Soziolinguistika}

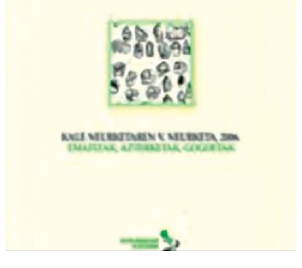

10. «Taula berean sartzen dira hiru eskualdetako emaitzak ehunekotan adinaren arabera, kostaldetik barnealdera, jakinez kondu batzu dudazkoak direla lagina eskasez» (Baxok, Euskararen egoera Ipar Euskal Herrian: 21). 


\subsection{Kale erabilera neurketa: behaketa zuzena, inkestatzailearen parte hartze gabekoa}

Hau da beraz Euskal Herrian egiten den bigarren inkesta soziolinguistika nagusia, metologikoki osoki desberdina. Hemen erabilera ez da « aitortua edo subjektiboa » (Altuna, 2007: 22). Andoaineko Soziolinguistika Klusterrak inkesta horiek kudeatzen ditu, lau urtean behin 1989z geroztik. 2006an bosgarren neurketa izan zen. Iparraldeko hiru lurraldeak ez dira bereizi azken neurketa horren argitalpenean, 2007ko Bat Soziolinguistika aldizkariko 64. zenbakian.

\section{- Behaketa zuzena: datuen biltzeko era objektiboa}

Bigarren inkesta motak behaketa zuzenaren bidez emaitzak biltzen ditu eta, horrela, egiazko ahozko erabilera neurtzen du. Inkestatzailea ixilik egoten da eta bere ibilbidean datuak markatzen ditu $^{11}$. Beraz Eusko Jaurlaritzaren inkestetan ez bezala, mintzatzen ari denari ez dio deus galdatzen, entzuten du eta hizkuntza zein den era objektiboan biltzen du.

Behaketa bidezko datu-bilketa baita, hemen hiztunen irudikapenak eta jarrerak akats-iturburu ez daitezke izan. Iragazkirik ez dugu. Halere, neurketa soziolinguistiko horiek ere beren mugak, eskasiak badituzte.

\section{- Ikergai murritza: hizkuntzen kale erabilera}

Oraikotz, euskararen kale ahozko erabilerari mugatzen da. Beren aztergaia Eusko Jaurlaritzaren inkestakoak baino are murritzago da beraz. Holako neurketak egin lirateke zerbitzu publikoetan, lantegietan, saltegietan, ostatuetan... Hots, eremu publiko oroetan.

Bistan da, zuzeneko behaketaren bidezko euskararen erabileraren neurketa etxean, hurbileko komunitatean, lagunekin, auzoekin, hots harreman-sare informaletan, eremu intimoagoetan ez litzateke kalean bezain erraza. Baina hor, kaleari mugatuz, hutsune handia badugu.

\section{- Hiztunen ezaugarri batzuk ezezagunak dira: adina, jatorria}

Inkestatzaileak neurtzen dituen pertsonen ezaugarri batzuk biltzen ditu: erabilia(k) d(ir)en hizkuntza(k) bistan dena, baina ere adina, sexua, talde tamaina eta hiztunen artean haurrik den.

Behaketa egiten duenak hiztunaren adina ez daki zein den, estimatzen baizik ez du (Coyos: 109). Eta lau adin-talde desberdinen kokatu behar du: haurrak (0-14 urte), gazteak (15-24 urte), helduak (25-64 urte) eta adinekoak (65 urtetik gorakoak). Sailkatze hori beraz ez da fidagarria, inkestatzaileen estimazioan oinarritua baita.

Kontuan hartua den hiztuna neurtutako udalerrian bizi den edo beste nonbaitik etortzen den jakitea ez da posible (ibid.). Jakinez jendea erosketen egiteko hiri handietara joaten dela, segur da neurtuak diren denak tokikoak ez direla. Ziurgabetasun horrek emaitzen balioa murrizten du ere, emaitzen fidagarritasuna txikitzen du. Euskalkiak kontuan hartzeko lirateke, baina hori ere ez litzateke aski jakiteko hiztuna hirikoa den ala ez.

Ondorioz Olatz Altunarekin erran dezakegu: « Emaitzak adierazgarriak dira eskualde, lurralde eta Euskal Herri mailan. Ez ordea udalerri mailan, udalerri gehienetan jasotako elkarrizketa kopurua ez baita nahikoa ondorioak ateratzeko».

\section{- Erabileraren neurketa memento berezi batekoa eta ez egunerokoa}

11. «Hortaz, kalean entzuten diren elkarrizketak neurtzen dira, eta neurtzaileek jasotzen dituzten datuek entzun eta zenbatu diren pertsona horiek leku eta une horretan zein hizkuntza zerabilten adierazten dute, ez besterik. Horrek ez du esan nahi, "horiek bakarrik direnik euskaraz egiten dutenak, baizik eta hori dela euskararen erabilpenaren proportzioa; alegia, ez dugu jakingo zenbatek egiten duen, baizik eta batez beste, zenbat egiten den euskaraz une eta leku bakoitzean », Olatz Altuna (IV. kale neurketa, Klusterreko webgunea, http://www.soziolinguistika.org). 
Ipar Euskal Herrian, adibidez, 2006ko behaketa urriaren 18an eta 2lean egin zen, 10:00etarik eguerdi arte eta 16:00etarik 18:00etara «kalean jende gehiago behatu ahal izateko» erraten digute (Altuna: 24). Baina, bistan da, hor egunorozko erabilera ez dugu baina bai iraupen laburreko denbora-tartekoa. Hori ere kontuan hartzeko da emaitzen ebaluatu nahi ditugunean. Emaitzak ez dira urte batekoak, baina bai hiru egunetako aldi motz bateko emaitzak.

\section{- 1.000 biztanletik beherako udalerriak kontuan ez hartu}

Ipar Euskal Herriko kasuan 1.000 biztanletik gorako 11 herri kontuan hartuak dira, jakinez 38 zirelarik 2001ean, erran nahi baita 1.000 biztanletik gorako udalerri guziak orduan. Aldiz, 1.000 biztanletik beherako herriak ez dira kontuan harturik, Atharratze ez ezik 2006an. Beraz barnekaldeko herri euskaldun gehienak baztertuak direla erran dezakegu, Iparraldeko eremu eskualdunenak partzialki kontuan hartuak baitira: Nafarroa Beherean bi udal handienak bakarrik eta Zuberoan ere.

Halere, barnekaldeko biztanleria ez da hain gora eta beraz bere eraginak emaitzetan ez dezake hain handia izan.

\section{- Hautatu lekua: zein ibilbide, zein auzo?}

Hona azken zalantza bat, hiriekin pausatzen dena. Argitalpenean erraten dute « kalerik jendetsuenak, plazak, parkeak, jolastokiak, karrikak »neurtzen dituztela (Bat, 64: 22). Baina inkestatzailearen ibilbidea nola hautatu? Har dezagun Baiona adibidez. Baiona handiko Thiers karrika Baiona ttipiko Pannecau karrika baino jendetsuago da. Halere, euskara azken hortan Thiers karrikan baino erabiliagoa dela pentsa dezakegu. Beraz hor ere ponderazioa beharrezkoa litzateke.

\section{Ondorio gisa: alde batetik argazki bat, irudi bat bestetik}

Euskararen kasuan, bi inkesta soziolinguistiko mota nagusi ditugu Euskal Herri osoa aztergaitzat hartzen dutenak. Batak emaitzak behaketa zuzenaren bidez biltzen ditu eta ez, beraz, aitorturiko erantzuni esker, ustezko gaitasuna edo erabilera biltzen. Datu horiek zinez baliagarri eta beharrezkoak dira jakinez egiazko ahozko erabilerari buruzkoak bakarrak direla. Hortan da segur lan horren berezitasun garrantzitsuena. Baina neurtua dena zinez mugatua da, urteko une baten erabilia den kale hizkuntza zein den eta urteetan zehar erabilera horren joera. Argazki bat ematen digu, bapateko argazki bat.

Bigarren inkesta motarekin herritarren hizkuntza-gaitasuna, euskararen transmisioa, euskararen erabilera eta euskararekiko jarrerak aztertzen dira. Emaitzen fidagarritasuna ez da lehen inkesta motan bezain handi. Datuak inkestatuen jarreren eta irudikapenen iragazkitik iragaiten dira. Baina ohartu gara ere, azkenean, egiazko kopuruen, egiazko ehunekoen ezagutzea ez dela hain garrantzitsua. Inkesta soziolinguistikoen emaitzak adierazle dira, ez besterik. Errealitatearen irudi aski garbi bat ematen dute eta ez gehiago ${ }^{12}$. Irudi argigarria.

Horregatik soziolinguistikak ekoizten dituen datuak eta emaitzak zuhurtasunez hartu behar

12. Ildo honetan ados naiz Mikel Zalbidek erraten duenarekin, inkesta horiek erabilera etxean ebaluatu nahi dutenean: « Lapiko horretan egosten da etxeko hizkuntza, ez bost edo hamar urtean behin zentsuko papera betetzerakoan ematen den erantzun hotz eta sinplifikatuan. Demolinguistikazko azalpen estatistikoak eta azterlanak ez da gutxiestea komeni, zenbaitek errazegi egin ohi duenez: balio handia dute, beren esparruan eta beren neurrian. Baina egiaren zatitxo bat erakusten dute datu horiek, ez egia osoa », HP21. Oinarrizko Txostena irakurri ondoko zenbait ohar, blog.euskara21.euskadi.net/uploads/file/Batzordekideen\%20ekarpenak/mikel-zalbide_eus(1).pdf. Halere, lan honetan egia nozioa baino errealitatea nozioa erabiltzen dut. Gure helburua da jakitea errealitate soziolinguistikoa zein den. 
ditugu.

\section{Bibliografia}

Altuna Olatz, 2007, Euskal Herriko kale erabileraren neurketa. Ikerketaren nondik norakoak, Kale erabileraren V. neurketa 2006. Emaitzak, Azterketak, Gogoetak. Bat Soziolinguistika aldizkaria, 64, Andoain, Soziolinguistika Klusterra: 21-31.

Baxok Erramun, [datarik gabe], 2008an hedatua, Euskararen egoera Ipar Euskal Herrian - La situation de la langue en Pays Basque de France, Euskararen Erakunde Publikoak eskatutako azterketa lana, fotokopi elebiduna.

Blanchet Philippe, 1994, Problèmes méthodologiques de l'évaluation des pratiques sociolinguistiques en langues « régionales » ou « minoritaires »: l'exemple de la situation en France, Langage et société, 69, Paris, 93-106.

Bourhis Richard, Landry Rodrigue, 2008, Group Vitality, Cultural autonomy and the Wellness of Language Minorities, in Bourhis Richard Y., The Vitality of the English-Speaking Communauties of Quebec, Montréal, Universités de Montréal et de Moncton, 185-212 ; eta euskaraz ere:

- 2008, Hizkuntza-gutxiengoen talde-bizindarra, kultura-autonomia eta ongizatea, Bat Soziolinguistika aldizkaria, 67, Andoain, Soziolinguistika Klusterra, 151-192..

Calvet Louis-Jean, Dumont Pierre zuzend., 1999, L'enquête sociolinguistique, Paris, L'Harmattan.

Coyos Jean-Baptiste, 2007, Euskararen kale erabileraren V. neurketaren emaitzez Ipar Euskal Herrian, Bat Soziolinguistika aldizkaria, 64, Andoain, Soziolinguistika Klusterra, 109-116.

Euskararen Aholku batzordea, 2008, Oinarrizko txostena, XXI. mende hasierarako hizkuntza politikaren oinarriak, 2008ko apirilak 29, Eusko Jaurlaritza, blog.euskara21.euskadi.net/.../file/ Oinarrizko_Txostena.pdf.

Eusko Jaurlaritza, 2008, IV. Inkesta Soziolinguistikoa 2006, Eusko Jaurlaritzaren Argitalpen Zerbitzu Nagusia, Gasteiz.

Siadeco ikerketa aplikatua, 2006, 7. Galdetegi eredua - IV. Soziolinguistikazko Inkesta - 2006. urtea Iparraldea, 29-37.

Soziolinguistika Klusterra, 2007, Kale erabileraren V. neurketa 2006. Emaitzak, Azterketak, Gogoetak. Bat Soziolinguistika aldizkaria, 64, Andoain, Soziolinguistika Klusterra. 